\title{
MODAS DE MULHER, MODOS DE COMÉRCIO: CAMADAS MÉDIAS, CULTURA E ECONOMIA NA HISTÓRIA DO CONSUMO MODERNO
}

\section{Everardo Rocha* \\ Marina Frid ${ }^{* *}$ \\ William Corbo $^{* * *}$ \\ Pontifícia Universidade Católica do Rio de Janeiro - Brasil}

Resumo: O objetivo deste trabalho é investigar a recorrência de relações entre distintos movimentos do consumo na modernidade, a formação das "classes médias" e a construção do ideal da "mulher moderna". Vamos analisar as formas pelas quais um determinado modelo de negócios, inaugurado pelos grandes magazines em meados do século XIX, estrutura um sistema para o comércio de bens e serviços que contribui para inserir contingentes das populações urbanas de camadas médias no universo do consumo e a mulher em atividades de compra. Este estudo analisará três contextos de expansão do consumo nos quais se evidencia a complexa relação entre economia e cultura: a emergência dos grandes magazines nas cidades europeias em meados do século XIX; o surgimento dos shoppings nos Estados Unidos após a Segunda Guerra Mundial; a chegada de marcas internacionais no Brasil a partir dos anos 2000, especificamente o caso da rede de lojas Forever 21.

Palavras-chave: classes médias, cultura e economia, história cultural do consumo, representações da mulher.

Abstract: This paper aims to investigate the recurrent relationship between different consumption movements in modernity, the forming of "middle classes" and the construction of the "modern woman" ideal. The work analyzes how a specific business model, which was inaugurated by grand magazines in the mid-nineteenth century,

\footnotetext{
* Contato: everardo@puc-rio.br.

** Doutoranda em Comunicação. Contato: marina_frid@yahoo.com.br.

*** Doutorando em Comunicação. Contato: wacorbo@gmail.com.
} 
structures a system for selling goods and services that contributes to include masses of middle class urban populations in the universe of consumption, particularly by associating women to shopping activities. This study will focus on three contexts of expanding consumption where the complex relationship between economy and culture becomes evident: the emergence of grand magazines in European cities during the mid-nineteenth century; the development of shopping malls in the United States after the Second World War; and the arrival of international brands in Brazil from early 2000s, especially the case of the retail chain Forever 21.

Keywords: cultural history of consumption, culture and economy, middle classes, representations of women.

\section{Introduç̃o}

O objetivo deste estudo é analisar a recorrência das relações entre os diferentes movimentos do fenômeno do consumo na modernidade, a formação das chamadas "classes médias" e a construção do ideal da "mulher moderna". Mais especificamente, pretendemos investigar as formas pelas quais um determinado modelo de negócios, inaugurado na segunda metade do século XIX com os grandes magazines, estrutura um sistema para o comércio de bens e serviços que contribui decisivamente para envolver contingentes, cada vez mais amplos, das populações urbanas de “camadas médias” (Velho, 1981) no universo do consumo, sobretudo, pelo estímulo à participação da mulher em atividades de compras e como força de venda. Assim, vamos examinar três diferentes contextos e experiências históricas nas quais podemos perceber as complexas relações entre economia e cultura, e como movimentos sociais propiciados por processos de consumo em expansão são capazes de correlacionar inovações na dinâmica comercial com o recrutamento de novos públicos de consumidores, possibilitando a inclusão de parcelas da sociedade em espaços e práticas anteriormente restritos. Como o estudo de cada um desses momentos demonstra, essa correlação se realiza particularmente através da mulher e sua crescente inserção na esfera pública. Os diferentes contextos que tomamos como emblemáticos para o estudo em questão são: a emergência dos grandes magazines nas cidades europeias entre meados do século XIX e início do século XX; a expansão dos shoppings nos subúrbios dos Estados Unidos durante o período subsequente à Segunda Guerra Mundial; a chegada recente,

Horizontes Antropológicos, Porto Alegre, ano 22, n. 45, p. 217-247, jan./jun. 2016 
principalmente a partir dos anos 2000, de marcas internacionais no Brasil, em especial o caso da norte-americana Forever 21, cadeia varejista de moda.

A reflexão sobre classes médias no campo das ciências sociais não é algo recente e muito menos de fácil entendimento. Em sua ampla obra dedicada à compreensão da estrutura e dos processos particulares do capitalismo, Marx (1974, 2006; Marx; Engels, 1978) apresentou algumas teses sobre os grupos sociais intermediários, aqueles que não poderiam ser considerados proletários e nem pertenciam ao mundo burguês stricto sensu - uma pequena burguesia com acesso à propriedade e também um conjunto de empregados assalariados. Em suma, no modelo marxista, a divisão da sociedade em classes é definida pelo lugar que elas ocupam na produção, com exceção à existência dos segmentos intermediários, que não estaria fundamentada, necessariamente, nessa premissa (Lukács, 1971). Por outro lado, contribuindo para as discussões sobre classes, Weber (1999) analisou atentamente a formação das burocracias que, em larga medida, foram responsáveis por contribuir com um grande número de indivíduos para o contingente de classes médias tanto no caso europeu quanto na experiência norte-americana. Weber (1971) define classe social como algo diretamente relacionado a possibilidades de oportunidades de vida previamente determinadas pelo mercado. Assim, os interesses das classes sociais corresponderiam às suas posições no mercado, que, por sua vez, seria 0 responsável por gerar um arsenal de escolhas para os diferentes grupos.

Ao tratar especificamente da temática da classe média e aproveitar a expansão do conceito de classe social promovida por Weber, Wright-Mills (1979) realiza um profundo estudo sobre a formação da "nova classe média" norte-americana, os chamados white-collars. O autor investiga a decadência dos pequenos proprietários e o crescimento dos grandes players na economia dos Estados Unidos durante a primeira metade do século XX e nos anos posteriores à Segunda Guerra Mundial. Wright-Mills compreende a classe média para além da propriedade, evidenciando as possibilidades de contato dos segmentos extremos desses white-collars com burgueses, de um lado, e proletários, de outro. Destaca, principalmente, as atividades de trabalho dividindo os white-collars em cinco "mundos" fundamentais estruturados em termos de ocupações, como veremos adiante. Esse movimento da sociedade estimulou a formação de um grande contingente de profissionais como administradores, publicitários, profissionais de escritório, vendedores, ambulantes, gerentes e deu origem a uma classe média interpretada pelo autor como uma espécie de pirâmide dentro da 
pirâmide das hierarquias sociais, como um grupo heterogêneo em posições políticas, crenças e valores. A perspectiva de Wright-Mills (1979) contribui para o estudo das classes médias, pois ela vai além da posição dos integrantes do grupo na esfera da produção e entende que, apesar de não serem proprietários, esses indivíduos realizam trabalhos especializados, são dotados de habilidades profissionais, gerenciam funcionários e se aproximam ora da burguesia, ora dos trabalhadores manuais, constituindo, portanto, uma classe específica.

De fato, nosso estudo pretende demonstrar, através de diferentes contextos e experiências históricas, como a formação, a visibilidade e o imaginário moderno-contemporâneo relacionado às ditas classes médias são recorrentes e conectados às transformações na esfera do consumo. Particularmente, se pode apontar a incorporação de um amplo contingente de mulheres às camadas médias - e a própria questão da emancipação feminina - como algo vinculado à expansão do consumo que ocorre, principalmente, a partir de meados do século XIX com o surgimento das primeiras lojas de departamentos. Embora envolvendo fatores de ordem muito mais abrangente, os movimentos pela emancipação da mulher acontecem simultaneamente ao crescimento do consumo e da cultura de massa. No presente artigo, portanto, procuramos identificar os diversos pontos em que esses dois processos se intersectam e dialogam. Como sugere Leach (1984), a mulher não só participa, mas é em si decisiva à formatação de uma cultura de consumo. A complexa relação que se estabelece entre mulheres e compras na modernidade é fato gerador de uma profunda ambiguidade, que se expressa seja no plano das representações femininas na mídia (Goffman, 1987; McLuhan, 1951; Rocha, 2013), seja no interior das diferentes correntes do movimento feminista (Krolokke; Scott, 2006; Meyerowitz, 1994). Este trabalho, no entanto, não pretende dar conta das múltiplas questões de gênero, poder e usos da imagem da mulher para fins de consumo, amplamente debatidas por diferentes autores (De Grazia; Furlough, 1996; Goldman; Heath; Smit, 1991; Kilbourne, 2000). Nosso objetivo é examinar as relações entre economia e cultura, através do exame das inovações no sistema do consumo e como promovem o recrutamento de sempre novos públicos tendo, invariavelmente, a mulher como protagonista da expansão. Dessa forma, buscamos reforçar a centralidade do consumo como arena de participação e expressão social (Douglas; Isherwood, 2004), bem como contribuir para as reflexões sobre os intricados vínculos entre a figura feminina e as atividades de compras (Miller, D., 2002). 
Para realizar essa tarefa, em um primeiro momento vamos investigar o nascimento dos grandes magazines nos centros urbanos europeus a partir de meados do século XIX e como esses empreendimentos aproximam uma quantidade significativa de indivíduos originários de estratos mais baixos aos hábitos, bens de consumo, estilos e gostos típicos da burguesia da época. A análise destaca que o modelo de negócios inaugurado pelos grandes magazines pode ser assumido como uma espécie de precursor dos shoppings e redes de lojas que hoje são lugares-comuns nas paisagens urbanas. Afinal, diversas técnicas de venda, distribuição, marketing, publicidade e design foram introduzidas por essas "catedrais" do consumo moderno, como nomeadas por Émile Zola em seu clássico Au bonheur des dames, de 1883 (Zola, 2008). Essas técnicas, que há mais de 150 anos aumentaram de forma expressiva o universo de consumidores, são até hoje, mutatis mutandis, aplicadas por grandes empreendimentos comerciais e marcas consagradas. Além disso, outro fator importante dos grandes magazines é a representatividade dos seus milhares de funcionários e empregados que constituíram, eles próprios, parte do contingente das "novas classes médias" europeias e norte-americanas da época, com destaque para as vendedoras, que desempenharam uma função central na projeção de novos lugares sociais para a mulher como trabalhadora e consumidora. Embora esse modelo de negócios tenha se expandido rapidamente para as Américas, inclusive o Brasil, ${ }^{1}$ a análise privilegia o contexto europeu em linha com a massa crítica já disponível de estudos que examinam os impactos das lojas de departamentos na vida social de metrópoles como Paris e Londres entre meados do século XIX e início do XX (Au bonheur..., 2011; Hahn, 2009; Leach, 1984; Miller, M., 1981; Rappaport, 2001; Verheyde, 2012).

Após a análise do contexto dos grandes magazines, nosso estudo avança para o período imediatamente posterior à Segunda Guerra Mundial e investiga as condições para a expansão do consumo nos centros urbanos dos Estados Unidos interligadas à categoria dos white-collars e à construção dos shoppings. Pois, como observa Wright-Mills (1979), para a classe média norte-americana, o comércio em meados do século XX deixa de ser uma opção e se torna um tipo de atividade totalizante, ou seja, de abrangência ilimitada, envolvendo

\footnotetext{
1 No caso brasileiro, por exemplo, vale destacar o grande magazine Parc Royal, que abriu suas portas em 1873 no Rio de Janeiro (Gorberg, 2013), além do Mappin Stores, que inaugurou suas atividades em 1913 na cidade de São Paulo (Bonadio, 2007).
} 
quase todos os atores sociais em seus processos, técnicas e práticas. Segundo a perspectiva do autor, naquele momento o mercado passa a atravessar toda e qualquer instituição e relação social. Em larga medida, esse envolvimento se concretiza com um acentuado desenvolvimento dos shoppings, com suas estruturas gigantescas que disponibilizam uma profusão de mercadorias à venda para toda e qualquer pessoa com poder de compra. Por um lado, os white-collars servem ao mercado como funcionários e prestadores de serviço direta ou indiretamente ligados a esses empreendimentos; por outro, são eles próprios parte substancial do contingente de consumidores visados pelos enormes centros comerciais. O período analisado por Wright-Mills se caracteriza ainda pelo retorno dos homens ao mercado de trabalho após a guerra, acentuando as tensões sobre o lugar social da mulher, e pelo afastamento entre os espaços da família e do trabalho com a migração dos lares para os subúrbios ao redor das grandes metrópoles (McLuhan, 1951; Meyerowitz, 1994).

No tempo presente, a última parte do artigo examina aspectos da ascensão de uma "nova classe média" no Brasil - tema amplamente explorado na mídia e discutido por diversas perspectivas acadêmicas (Neri, 2012; Yaccoub, 2011) -, tendo como objeto de análise o caso da Forever 21. Dentre outros importantes fatores, o lugar de destaque alcançado pelo país no cenário político-econômico internacional e as estimativas de um potencial de milhões de consumidores atraíram, nos últimos anos, diversas empresas estrangeiras que iniciaram ou expandiram suas operações em cidades como São Paulo, Rio de Janeiro, Brasília, Porto Alegre, Curitiba e Ribeirão Preto. O crescimento do consumo na direção de camadas da população antes sem acesso às possibilidades de compras gerou um intenso debate sobre os anseios, gostos, prioridades e novos hábitos adquiridos pelo grupo de brasileiros emergentes. Em nosso estudo, destacamos o caso da chegada, no primeiro semestre de 2014, da rede de lojas Forever 21, que teve grande repercussão por atrair milhares de jovens, a maioria mulheres, para longas filas nas inaugurações de suas primeiras lojas no Rio de Janeiro e em São Paulo. A Forever 21, uma das principais marcas mundiais do segmento fast-fashion, é voltada principalmente para um público jovem e tem como principal característica a promessa de sempre disponibilizar em suas lojas novos modelos de roupas e acessórios da "última tendência”, com rápida reposição e baixos custos. Ao trazer uma moda internacional a preços acessíveis e diretamente ligada, sobretudo, à ideia de juventude, a Forever 21 é modelar para tratarmos da inclusão das "novas classes médias" 
na esfera do consumo no atual contexto brasileiro e, especificamente, da concepção de um ideal de "mulher moderna", autônoma e com poder de compra.

Em suma, vamos analisar os grandes magazines europeus, os shoppings norte-americanos e a marca contemporânea Forever 21, mostrando como esses modelos de negócios, permeados por transformações culturais e respeitados seus respectivos contextos, articulam-se com o recrutamento de consumidores, principalmente mulheres, em um permanente processo de criação de "novas classes médias” que se integram ao cenário do consumo. Seus respectivos projetos e modelos de negócio permanecem muito semelhantes: acelerar a reposição de produtos, praticar baixos preços, tornar acessíveis bens antes restritos às elites e realizar intervenções publicitárias. Se no caso dos grandes magazines europeus e dos shoppings norte-americanos o eixo de inclusão foi, entre outros, as técnicas comerciais e as inovações introduzidas nas relações de trabalho, no caso da marca contemporânea, a inclusão se traduz, além disso, através de uma narrativa de juvenilização que disponibiliza uma moda "elitizada” para um público mais amplo. Em todos esses contextos, a mulher - em suas representações e práticas - permanece como o elo principal na articulação entre as transformações nos modelos de consumo e o recrutamento de uma "nova classe média” que os sustenta.

\section{Burguesias, sufragistas e os grandes magazines na Europa}

A partir da segunda metade do século XIX, uma nova modalidade de comércio, surgida em algumas das principais cidades europeias, torna-se elemento central para a consolidação do fenômeno do consumo na modernidade. Os grandes magazines acontecem efetivamente no período que Karl Polanyi (2012) classificou como os “cem anos de paz”, entre 1815 e 1914, quando, diante da repercussão da Revolução Francesa, as principais potências mundiais passam a concentrar todos os seus esforços no desenvolvimento da capacidade industrial e na manutenção de uma paz universal saudável para os negócios. Mudanças na ordem cultural, nos costumes e nos gostos forneceram as bases para a formação de um sistema de consumo mais dinâmico e de maior alcance. Os grandes magazines são então favorecidos por uma convergência de fatores, entre os quais: a expansão de um sistema midiático, a reestruturação das cidades, o aperfeiçoamento das técnicas de marketing e design, a exaltação do estilo de vida burguês, o estímulo ao gasto do Romantismo, o 
crescimento do consumo de saberes, as mudanças no papel da mulher na sociedade, entre outros. (Au bonheur..., 2011; Campbell, 2001; Darnton, 1996; Hahn, 2009; Miller, M., 1981; Rappaport, 2001).

De fato, os modos de sociabilidade e as estratégias de vendas introduzidas pelos grandes magazines estruturaram muitas das práticas de consumo tal como as experimentamos hoje (Rocha; Frid; Corbo, 2014). Empresários pioneiros do modelo de negócios dos grandes magazines, como Aristide Boucicaut, proprietário do Bon Marché, fundado em 1852 em Paris e tido como o primeiro grande magazine do mundo, representam bem aquilo que Max Weber (2004) indica como "perturbação ao aconchego" da economia tradicional, uma espécie de força que retira da zona de conforto os pequenos comerciantes que predominavam até então. A figura do empreendedor, capaz de experimentar rápida ascensão econômica e social, nutriu as expectativas de riqueza, prestígio e fama do imaginário burguês. Émile Zola (2008) o reproduziu em Octave Mouret, personagem dono da loja de departamentos Bonheur des Dames que dá o título ao seu romance, provavelmente inspirado em Boucicaut, que de fato nascera filho de um humilde chapeleiro e ao morrer em 1877 tinha um patrimônio estimado em 22 milhões de francos (Gay, 2002). Na realidade, porém, somente um pequeno número de burgueses alcançou tamanha projeção. Casos de enriquecimento em velocidade vertiginosa e de cifras impressionantes como os de John Rockefeller e Andrew Carnegie foram excepcionais, mas a fortuna "[...] adquirida por ambos produzia histórias que estimulavam a fantasia” (Gay, 2002, p. 29).

Ainda segundo Peter Gay (2002), as camadas médias na Europa do século XIX, mesmo se expandindo de forma significativa, não constituíam um todo coeso em termos de aspirações políticas, desenvolvimento econômico, questões de religiosidade, atitudes perante a autoridade, entre outros aspectos. Ao longo dos cem anos que precederam a Primeira Guerra Mundial, os estratos medianos e superiores do complexo amálgama que era a classe burguesa aumentaram em número, fortuna e expressividade política, enquanto os inferiores cresceram apenas em quantidade. Como indica Gay (2002), a demanda por serviços de nível mais baixo entre aqueles da classe média - escriturários, balconistas, vendedores, entre outros - tornou-se cada vez maior com o crescente aparelhamento do governo e a expansão da indústria, dos bancos, das seguradoras, e também do comércio. Na Alemanha, por exemplo, o contingente de funcionários administrativos aumentou sete vezes. Com essa dilatação da pirâmide 
da burguesia europeia, as camadas mais baixas acabaram por receber nomes específicos, como Mittlestand na Alemanha e nouvelles couches na França.

Pode-se dizer que um traço comum entre as diversas classes médias do século XIX estava na valorização da autonomia e na perspectiva de serem indivíduos livres, capazes de determinar seus próprios rumos, ainda que balizados pelas normas e pela moralidade da família, da sociedade e do Estado. Nesse contexto, os grandes magazines foram influentes no processo de emancipação feminina, tanto por colocarem o consumo como atividade prioritariamente de mulheres quanto por abrirem campo para elas no mercado de trabalho. Assim, as mulheres atuantes no mercado como trabalhadoras e consumidoras passaram a ocupar o centro de uma das mais relevantes esferas da vida social; em certo sentido, foram responsáveis por modelar a cultura do consumo (Leach, 1984). Os serviços oferecidos pelos grandes magazines - refrescos para os clientes, bistrôs, restaurantes, bibliotecas, salas de repouso - e seus anúncios publicitários contribuíam para a construção de um imaginário sobre as práticas de consumo como experiências singulares e personalizadas. Desse modo, os grandes magazines se firmavam como espaços aptos a satisfazer aos anseios e expectativas tanto sociais quanto individuais (Rappaport, 2001).

Entre meados do século XIX e início do XX, os grandes magazines constituíam espaços públicos especificamente forjados para a sociabilidade feminina. Assim, em uma via de mão dupla, a mulher tanto impulsionou o consumo como se beneficiou dele em seu processo de emancipação (Au bonheur..., 2011; Leach, 1984; Rappaport, 2001). Os grandes magazines funcionavam como espaço de comunicação ao espelhar e construir o modus vivendi burguês com vendedores/as bem vestidos/as, polidos/as e especialistas em tratar a sua clientela preferencial, as mulheres, como verdadeiras "rainhas". Segundo Miller, M. (1981), os grandes magazines proporcionavam em seus ambientes uma extensão do estilo de vida dominante, ampliando o acesso a esses valores traduzidos nos bens expostos em suas prateleiras.

Ao transformar o espaço de venda em espaço de comunicação e fazer do ato da compra uma experiência prazerosa e memorável, os grandes magazines propuseram novos gostos, hábitos, comportamentos e alternativas de sociabilidade. Essas lojas atuaram de forma pedagógica, materializaram valores da burguesia ascendente tornando o consumo um fim em si mesmo e constitutivo da experiência cotidiana nas grandes cidades. Segundo Verheyde (2012), os seis métodos comerciais estabelecidos para sustentação do modelo de negócio 
dos grandes magazines foram: a fixação e exibição dos preços, a redução dos custos aliada ao aumento das vendas, a livre entrada dos consumidores nas lojas, a criação de diferentes seções com produtos variados, a política de devoluções e o investimento na publicidade. No modelo empresarial dessas lojas, o objetivo central era facilitar e incentivar a compra através de todos os artifícios possíveis.

Em sua análise, Miller, M. (1981) observa que a estratégia do Le Bon Marché consistia, principalmente, em encurtar o fluxo de bens dos produtores às mãos dos consumidores, aumentando o giro de mercadorias, o volume de vendas e a consequente entrada de receitas no caixa. A aceleração do consumo era algo central na lógica financeira dos grandes magazines, baseada na venda massificada com margens reduzidas de lucro aliada à produção em larga escala. Assim, as lojas de departamentos representaram o primeiro passo na extensão do luxo e das atividades de consumo para uma maior parcela da sociedade (Lipovetsky; Roux, 2005). O crescimento desse modelo de lojas implicou diversas transformações nos hábitos, gostos e práticas não só entre as mulheres e homens da alta burguesia, mas também de seus próprios funcionários. Nesse sentido, o crescimento dos grandes magazines se relaciona com a formação de uma "nova classe média" consumidora, tal como observado por Miller, M. (1981), que apontou a ascensão social dos funcionários do Le Bon Marché como uma das consequências de sua consolidação. De fato, as lojas de departamentos ativaram novas sensibilidades que se vinculavam aos bens de consumo.

Em sua trama, Zola (2008) destaca o encantamento dos vendedores do "Paraíso das Damas" com os modos e costumes de seus clientes burgueses, gastando seus salários em compras, ingressos de teatro, restaurantes e passeios de finais de semana. As funcionárias protestavam contra as refeições pouco caprichadas oferecidas nos refeitórios da loja e se refestelavam com quitutes que podiam adquirir com o dinheiro ganho no trabalho. Despendiam ainda seus salários em acessórios e vestidos de seda para passearem nos dias de folga, quando podiam deixar o uniforme. Também os homens aproveitavam ao máximo esses momentos em bares, restaurantes, bailes e pistas de corrida. Não por acaso, em diversas passagens do romance de Zola, o personagem Octave Mouret descreve clientes e funcionários do Au Bonheur des Dames como bourgeoisie moyenne (Zola, 2008, p. 106) ou, mais frequentemente, como petites-bourgeoises (Zola, 2008, p. 129, 218, 304, 305, 316, 395, 515), 
indicando um novo grupo social constituído por mulheres e homens trabalhadores dos grandes magazines que foi também logo incorporado ao universo do consumo.

As novas camadas - as Mittlestand e nouvelles couches - confirmam as profundas mudanças sociais de sua época, embora, como sugere Gay (2002), a extensão dos benefícios que puderam usufruir foi, na realidade, bem limitada. Na prática, seus integrantes lutavam para arcar com todas as despesas que se acumulavam, desde aquelas referentes à alimentação e ao aluguel residencial. Luxo para eles era o consumo de produtos e serviços habituais aos burgueses de segmentos mais altos - jantar em restaurantes, comprar entradas para concertos, viajar nas férias, adquirir móveis confortáveis, ou encomendar um casaco novo -, permitindo-se extravagâncias pontuais no dia do pagamento. Mas, sobretudo, preocupavam-se em não decair para o proletariado, insistindo a todo custo em cultivar modos burgueses formais e educando seus filhos de acordo com os padrões éticos da burguesia (Gay, 2002). Distinguir-se dos proletários era fundamental para a então "nova classe média” europeia e participar do jogo do consumo era, portanto, crucial.

Rappaport (2001) analisa como a inauguração em 1909 da loja de departamentos Selfridges em Londres promoveu, na região do West End, uma forma de popularização do consumo para as camadas mais baixas da população urbana em um ambiente que se mantivera predominantemente relacionado à aristocracia e à alta burguesia. O proprietário Harry Gordon Selfridge aplicou todo o conhecimento que adquiriu nos 25 anos em que trabalhou na loja de departamentos norte-americana Marshall Field's para impulsionar a transformação das experiências de consumo na capital inglesa. Após a inauguração da loja, que mantinha suas vitrines acesas até a meia-noite para o prazer visual dos transeuntes, o West End londrino foi estabelecido como uma área onde diversos estratos sociais podiam desfrutar o prazer das compras. Segundo Rappaport (2001, p. 202), “Gordon Selfridge chegou até mesmo a afirmar que sua loja resgatou a sociabilidade dos mercados dos primeiros tempos modernos com sua cultura de mistura de classes e mistura de sexos”.

Entre fins do século XIX e início do século XX surge também a chamada "primeira onda" do feminismo (Krolokke; Scott, 2006). Movimento expressivo desse período foi o das sufragistas, que reivindicavam o direito ao voto às mulheres. Ao sair às ruas e discursar em público, as integrantes do grupo confrontavam os estereótipos de feminilidade da época, que atrelavam a mulher 
ao lar, deixando as questões políticas a cargo exclusivamente dos homens. Não obstante, as sufragistas buscavam destacar suas feições e elegância femininas com roupas nas cores lilás, branco e verde para, intencionalmente, mostrar como mesmo as damas tinham dignidade, pureza e esperança para se engajarem na vida pública (Au bonheur..., 2011). Os grandes magazines, espaços tanto de consumo como de trabalho para diversas mulheres, serviram às militantes como ponto de encontro e veículo de apoio às suas causas. Em Londres, Paris e também em grandes cidades dos EUA, lojas como a Selfridges cediam seus espaços para reuniões das sufragistas, assim como investiam em publicidade nas suas revistas (Au bonheur..., 2011; Leach, 1984). A série para televisão Mr. Selfridge (2013-) mostra a atenção que o seu fundador dedicava ao público feminino, inclusive aliando-se ao movimento das sufragistas, oferecendo o café da loja para suas reuniões e ainda as homenageando com vitrines e produtos que faziam alusão às suas causas. $\mathrm{O}$ alinhamento entre os interesses das sufragistas e da Selfridges só foi abalado em 1912, quando militantes tentaram apedrejar as vitrines da loja, alegando exploração das funcionárias com ínfimos salários. Esse episódio, de certa forma, antecipa o acirramento da tensão entre a mulher e o consumo que ocorre posteriormente, no final da década de 1960, com as reorientações do movimento feminista, suas complexas ramificações e múltiplas direções contestatórias.

\section{White-collars, liberacão feminina e shoppings nos Estados Unidos}

O consumo, no caso dos shoppings dos Estados Unidos do pós-guerra, também é uma circunstância básica na formação e recrutamento de uma "nova classe média”, dessa vez classificada por Charles Wright-Mills (1979) como white-collars. Nas principais cidades norte-americanas, as lojas de departamentos também já estavam presentes desde a segunda metade do século XIX. Entre as pioneiras, podemos citar a Macy's, inaugurada em 1858 em Nova Iorque, a Wanamaker's, em 1877 na Filadélfia e a Marshall Field's, que se expande após o grande incêndio de Chicago, em 1871. Apesar da existência de grandes magazines em praticamente todas as principais cidades do país, o que chama atenção nesse contexto e dialoga diretamente com a ideia de white-collars é o surgimento dos shoppings nos subúrbios dos Estados Unidos em meados do século XX, especificamente no pós-guerra. Diante do deslocamento da população para regiões periféricas, esses novos empreendimentos 
contribuíram para a descentralização das cidades e incentivaram de maneira intensa a articulação de uma "nova classe média” com as atividades de consumo.

Como afirma Don Slater (2002), no período do pós-guerra o consumo vive uma espécie de apogeu nos Estados Unidos, pois, do ponto de vista econômico, combinam-se a produção em massa típica da prática fordista e o foco administrativo keynesiano, que foram oportunos para a construção de uma grande riqueza. Como aponta o autor, em meados do século XX a economia norte-americana recebe a herança das políticas praticadas nas décadas anteriores e vive um período de grande crescimento da produção, dos investimentos, da infraestrutura e dos salários reais. É importante destacar que é nesse contexto que o Estado passa a regular de forma mais próxima os compromissos entre trabalhadores e patrões, assim como a acumulação de capital colhe os frutos do estímulo praticado nos anos anteriores, possibilitando dessa maneira um cenário favorável ao consumo. O contexto internacional efervescia com a crescente oposição entre dois modelos de sociedade, a capitalista - tendo os Estados Unidos como principal expoente - e a socialista - representada pela União Soviética. Desse modo, além de todo o cenário interno, os conflitos ideológicos no plano global faziam com que a cultura do consumo fosse estimulada e trabalhada de forma intensa, seja através do imaginário midiático, seja, principalmente, através da inclusão de indivíduos e grupos antes excluídos de uma série de espaços e experiências, como destaca Wright-Mills (1979).

A burguesia norte-americana do século XIX, diferente da europeia, era formada, essencialmente, por pequenos empreendedores rurais espalhados pelo país que possuíam, de fato, autonomia, e podiam praticar a livre iniciativa. Ao longo do século XX, porém, ocorre um processo de crescente concentração dos meios de produção, dando origem a negócios cada vez maiores nas mãos de poucos empreendedores. Dessa maneira, uma massa de homens e mulheres foi paulatinamente incorporada ao mercado como trabalhadores assalariados, a maioria em escritórios e exercendo funções administrativas ou de vendas, compondo uma "nova classe média" norte-americana menos autônoma, enfraquecida em sua influência política e mais heterogênea em termos socioeconômicos (Wright-Mills, 1979).

Em seu livro clássico A nova classe média, Wright-Mills (1979) indica que os white-collars incluem desde profissionais liberais como médicos, engenheiros e advogados até burocratas assalariados, gerentes de banco e vendedores de lojas. Portanto, esse grupo em si configura uma espécie de

Horizontes Antropológicos, Porto Alegre, ano 22, n. 45, p. 217-247, jan./jun. 2016 
pirâmide dentro da pirâmide social abrangente, na qual alguns estratos das camadas médias ainda se misturam em termos de renda e prestígio com a base, o proletariado, e, no polo oposto, alguns segmentos praticamente alcançam seu vértice, onde se situam os detentores dos meios de produção. De modo geral, o grande e intricado universo dos white-collars se divide em cinco grupos fundamentais que organizavam as camadas médias da sociedade norte-americana em termos de ocupações. Há o "mundo das antigas profissões” com médicos, engenheiros, advogados, professores, entre outras tantas especialidades que gravitam ao seu redor. O "mundo dos intelectuais" envolve escritores, pensadores, críticos, poetas, romancistas, jornalistas e editores. $\mathrm{O}$ "mundo administrativo" inclui secretárias, administradores, contínuos e gerentes. O "mundo dos escritórios” tem seus contadores, escriturários e datilógrafas. Finalmente, há o "mundo do magazine", com seus mais variados tipos de vendedores, de ambulantes, representantes de vendas e balconistas aos pesquisadores de mercado e publicitários.

Para Wright-Mills (1979), o "mundo do magazine” ganha destaque e se expande sobremaneira no pós-guerra, transformando as cidades norte-americanas em enormes espaços comerciais, onde vender e comprar se tornam atividades cotidianas quase mandatórias, perpassando a vida social urbana em todos os seus aspectos. No estudo de Padilha (2006), destaca-se que o primeiro shopping construído nos Estados Unidos data de 1950 e foi erguido nos arredores de Seattle. O novo modelo de comércio buscava, dentre outras coisas, expandir o consumo e solucionar os problemas relativos ao congestionamento de automóveis, uma modalidade industrial em franca expansão na economia norte-americana. Não por outro motivo, os shoppings tinham grandes espaços destinados ao estacionamento de carros e buscavam reproduzir toda a magia dos grandes magazines criados um século antes, tendo em seus interiores espaços de lazer, restaurantes, lanchonetes, espetáculos, lojas de marcas renomadas, banheiros públicos e assim por diante. Apesar da proximidade com o modelo das lojas de departamentos, o formato dos shoppings surge praticamente cem anos depois, quando a urbanização norte-americana e o forte crescimento econômico traziam consigo a necessidade de um rearranjo das cidades agora ampliadas na direção dos subúrbios e áreas mais periféricas. Com isso, o modelo inaugurado nas redondezas de Seattle foi rapidamente adotado em várias outras regiões dos Estados Unidos, com sucessivas construções de shoppings por todos os cantos do país em poucos anos. 
Aliado ao surgimento dos shoppings, em meados do século XX o "mundo do magazine" vive o seu auge. O crescimento das agências de publicidade em número e importância para as empresas anunciantes nutriu o imaginário de uma profissão $\mathrm{cool}$, prestigiosa e destacada dos demais vendedores. Durante os anos 1950, as agências investiram em novas técnicas de pesquisa, no contato frequente com o consumidor e em anúncios para a televisão, que se popularizava. A década de 1960, classificada como a era de ouro da publicidade nos Estados Unidos, é recontada pela premiada série de televisão Mad men (2007-2015), que retrata os célebres publicitários da Madison Avenue em seus dramas cotidianos: a competição por espaço no mercado; as disputas internas nas agências; a mulher como esposa, mãe e profissional; as relações na família; e o estilo de vida da classe média que se reveza entre o trabalho em Manhattan e o lar nos subúrbios nova-iorquinos.

Durante o período da Segunda Guerra, a mulher experimentou uma maior participação na esfera pública quando um grande contingente de homens foi deslocado para assumir funções militares. Terminado o conflito, a presença masculina novamente predomina no mercado de trabalho e muitas mulheres, sobretudo as casadas, voltam a se dedicar exclusivamente às atividades domésticas. As políticas públicas do pós-guerra nos Estados Unidos também contribuíam para nutrir um ideal de família que enfatizava a mulher nos papéis de esposa, mãe e dona de casa. Nesse contexto, as representações femininas sobressaíam na publicidade, apresentando ao mercado uma profusão de novos produtos e serviços, desde gadgets para facilitar os afazeres do lar até meias-calças de nylon. Um anúncio da época promete que um bom ferro de passar roupas ajuda a mulher a cumprir suas tarefas ao mesmo tempo em que cuida da sua relação conjugal: "Deixe Gladiron lhe ensinar a passar camisas sem odiar seu marido! Você vai amá-lo e amar seu Gladiron quando conseguir passar camisas em quatro minutos e meio [...]” (McLuhan, 1951, p. 32, tradução nossa). De forma espirituosa, o anúncio revela a tendência da "mulher moderna" que, tendo experimentado o mundo do trabalho antes do casamento, aceita ter marido e filhos, porém, cada vez mais rejeita as ocupações domésticas. Como observa McLuhan (1951), comprar aparelhos - assim como alimentos, sabão em pó, talheres, antisséptico bucal, meias - que aliviam o peso dos afazeres cotidianos se torna, assim, uma forma de expressar afeto; know-how fundamental para toda mulher em linha com o seu tempo. 
Quando, no final dos anos 1960, o movimento pela liberação da mulher é retomado com novas questões, uma delas polemiza a imagem da dona de casa, ostensivamente reproduzida na mídia, como indício de uma cultura opressiva. Para algumas feministas mais radicais - inspiradas por teorias marxistas, a psicanálise e textos como O segundo sexo de Simone de Beauvoir (1949) -, a relação entre o feminino e a domesticidade refletia a subordinação da mulher ao homem típica do patriarcalismo (Krolokke; Scott, 2006). Impulsionadas por outros movimentos de esquerda e de contracultura que aconteciam na época, as militantes da "segunda onda" (Krolokke; Scott, 2006) contestavam o estilo de vida capitalista e defendiam a liberdade sexual, a independência feminina e a igualdade de gêneros. Um episódio marcante foi o protesto de 1969 em Atlantic City nas proximidades do local em que acontecia o concurso de beleza Miss America. Durante a marcha, as feministas realizaram uma série de performances irreverentes, desde coroar uma ovelha como Miss America até jogar no lixo sutiãs, cintas, cílios postiços, sapatos de salto alto, maquiagens, entre outros produtos que para elas simbolizavam a opressão feminina. Desde então, intensifica-se o debate sobre as relações entre poder e consumo presentes nas representações da mulher e do corpo feminino na comunicação de massa.

\section{Juventude, Grrls e a moda da forever 21 no Brasil}

Em 15 de março de 2013, cerca de duas mil pessoas se misturaram nos corredores e formaram longas filas no Morumbi Shopping em São Paulo para conhecer a grande novidade. A primeira loja da Forever 21 no Brasil abriu suas portas nesse dia com um movimento intenso de consumidores, em sua maioria jovens mulheres, obtendo grande repercussão na mídia. Os visitantes desejosos por entrar na primeira filial brasileira da varejista, que chegou com a promessa de oferecer roupas da moda a baixos custos, esperaram por até cinco horas nos corredores do shopping com suas senhas em mãos. Na semana seguinte, a cena se repetiu no Rio de Janeiro na abertura da loja no shopping Village Mall, surpreendendo os frequentadores assíduos do centro comercial cujo ambiente é habitualmente tranquilo. Uma vez dentro da loja, os grandes desafios eram as filas para experimentar e pagar pelos produtos (Zuini, 2014).

A empresa chegou com a promessa de continuar oferecendo moda a preços acessíveis em suas filiais no Brasil, desafiando outros varejistas de 
fast-fashion já estabelecidos no país, como a multinacional C\&A e as locais Renner e Riachuelo (Carvalho, 2014). De fato, a chegada da Forever 21 ao mercado brasileiro segue o mesmo percurso recente de diversas marcas internacionais. A TopShop, uma concorrente da Forever 21, já havia aportado no Brasil desde 2012 (Top 5..., 2012). Popular entre consumidores da classe-média norte-americana, a Gap se estabeleceu no país em 2013. Outras grifes de moda de custo mais elevado como Michael Kors e Juicy Couture abriram lojas em cidades brasileiras nos últimos anos, além de diversas marcas dos mais variados segmentos, como chocolates Lindt, cosméticos de origem vegetal The Body Shop e a gigante tecnológica Apple. ${ }^{2}$

O contexto socioeconômico brasileiro dos últimos anos oferece algumas pistas para uma compreensão sobre o período que culmina com a entrada em série de marcas internacionais no país. De fato, a proliferação de empresas estrangeiras foi impulsionada por um momento interessante para o Brasil, quando o país alcançou uma posição privilegiada em meio a uma crise financeira global. A turbulência que atingiu as principais economias do mundo, especialmente os Estados Unidos e os países da União Europeia, foi antecipada pela primeira vez em 2007, teve seu auge em 2008 , e seus efeitos persistiram nos anos subsequentes. Entre outros fatores possíveis, a chamada "crise do subprime" foi causada principalmente por desregulamentação, alavancagem e aumento de empréstimos hipotecários de alto risco. Uma vez que a fragilidade de importantes bancos foi exposta e quando se tornou claro que dezenas de trilhões de dólares em derivativos eram de fato suspeitos e valiam muito menos do que o esperado, instituições financeiras foram desacreditadas, a confiança do mercado desapareceu e empresas começaram a quebrar (Shiller, 2008).

Um momento significativo aconteceu em 2008, quando o governo dos EUA se recusou a socorrer o banco de investimentos Lehman Brothers, permitindo que fosse à falência. Nesse mesmo ano, ao ser questionado sobre como a crise atingiria o Brasil, o ex-presidente Luiz Inácio Lula da Silva comentou: "Lá (nos EUA), ela é um tsunami; aqui, se ela chegar, vai chegar uma marolinha que não dá nem para esquiar” (Galhardo, 2008). E, como sugerido por um artigo no jornal francês Le Monde (Langellier et al., 2009), a percepção foi mesmo correta. O Brasil foi um dos últimos a ser pego na recessão e um

2 Ver Michael Kors... (2013), Grife... (2011), Scheller (2014), Salomão (2014) e Teixeira e Corrêa (2014).

Horizontes Antropológicos, Porto Alegre, ano 22, n. 45, p. 217-247, jan./jun. 2016 
dos primeiros a sair dela. Considerada uma economia emergente, juntamente com outros BRICs (O’Neil, 2001), o país foi reconhecido por especialistas e pela imprensa internacional como um dos pilares de crescimento e estabilidade. Essa imagem positiva foi reforçada pela reportagem de capa da The Economist de novembro de 2009: "O Brasil decola” (o título é acompanhado por uma imagem da famosa estátua do Cristo Redentor literalmente disparando como um foguete). Segundo a revista, houve certa descrença em 2001, quando especialistas indicaram o Brasil como uma das economias mais promissoras do mundo, uma vez que, naquela época, o país tinha "[...] uma taxa de crescimento tão minúscula quanto os seus biquínis” (Brazil..., 2009, tradução nossa). No entanto, em 2009, todas as dúvidas pareciam finalmente desaparecer.

De fato, a trajetória do Brasil em direção a essa imagem de 2009 não foi tranquila. Durante os anos 1980, o país gradualmente fez a transição de um período de ditadura militar de quase 30 anos para uma desejada redemocratização, que se concretizou com a eleição presidencial de 1989. Na década de 1990, o país passou por um processo inflacionário extremamente alto com práticas de indexação que aumentavam os preços a todo o momento. Essa fase de instabilidade começou a ser controlada em 1994, quando o então ministro da Fazenda, e futuro presidente, Fernando Henrique Cardoso sancionou o programa econômico brasileiro conhecido como Plano Real. Como consequência dessa nova agenda, foram necessárias alterações severas no sistema bancário que estava à beira do colapso. Por isso, em 1995, o governo instituiu o Programa de Estímulo à Reestruturação e ao Fortalecimento do Sistema Financeiro Nacional (Proer). Esse programa tinha como objetivo evitar a perda de credibilidade dos bancos, além de facilitar o processo de ajustes iniciado com o Plano Real. Em termos gerais, a finalidade do Proer era regulamentar as práticas bancárias para resguardar investimentos e poupanças da sociedade. O programa inibia, entre outras coisas, os empréstimos hipotecários conhecidos como subprime. À luz dos acontecimentos que foram parte central da crise que atingiu os Estados Unidos em 2008, levando à crise mundial, o Proer foi uma medida importante para a proteção da economia brasileira (Garcia; Giambiagi, 2010).

Mesmo com essas significativas intervenções governamentais, os mandatos de Fernando Henrique Cardoso são lembrados por iniciativas mais liberais, como a privatização de empresas estatais. Em 2001, Luiz Inácio Lula 
da Silva do Partido dos Trabalhadores (PT) venceu a eleição presidencial. Receou-se, então, que sua administração poderia comprometer o crescimento do setor privado, mas não foi o que aconteceu na economia brasileira e Lula se tornou um presidente muito popular no Brasil e famoso internacionalmente. O seu governo se caracterizou especialmente pela expansão de programas que visavam à inclusão social da população brasileira mais pobre, como o Fome Zero e o Bolsa Família. Esses esforços possibilitaram que, entre 2004 e 2010, mais de 32 milhões de brasileiros fossem inseridos na classe média e outros 19 milhões ultrapassassem a linha da pobreza (Neri, 2012). Foi em seu segundo mandato que a crise econômica abalou o mundo. A popularidade de Lula foi decisiva para manter o PT no poder. Tendo o seu apoio, Dilma Rousseff foi eleita como a primeira mulher presidente do Brasil em 2010.

O crescimento expressivo da classe média na primeira década dos anos 2000 foi amplamente repercutido na mídia, que dedicou inúmeros programas de televisão, matérias de jornal e reportagens de revistas em busca de conhecer "os hábitos e sonhos de cerca de 30 milhões de brasileiros que, só neste ano, serão responsáveis por R 620 bilhões em compras” (Todeschini; Salomão, 2009). Uma profunda correlação entre consumo e inserção social caracteriza a ascensão da "nova classe média" brasileira, marca que se tornou evidente na abundância de comentários jornalísticos sobre o fenômeno. A edição especial da revista Veja de maio de 2010 traçou o perfil de uma "nova mulher” no centro de uma classe emergente. Elas são trabalhadoras que assumem a chefia da família e, segundo as estatísticas apresentadas pela revista, "representam mais de 50\% dos clientes das farmácias, dos supermercados e das lojas de roupa" (Venturoli, 2010, p. 78). Com poder de decisão e de compra, "para cada dez homens de classe média que fazem compras nos shoppings, há doze mulheres” (Venturoli, 2010, p. 78). A mesma revista Veja apresenta a consultora de beleza Patricia, como uma personagem modelar:

Consultora de beleza, Patricia é responsável por $60 \%$ do dinheiro do lar. Ancorada no sucesso dela, a família trocou o fogão, comprou um computador com acesso à internet e estacionou na garagem um carro zero-quilômetro, comprado em 2008, em 24 prestações. "Prazo bem curtinho mesmo, que é para a gente não se meter em dívidas que não acabam mais”, diz Patricia. O próximo passo é trocar o televisor e terminar de pagar as prestações da casa própria em Itaquaquecetuba, na Grande São Paulo. "Lá teremos uma suíte para o casal”, afirma Patricia. (Venturoli, 2010, p. 76). 
Novamente, como em contextos históricos anteriores, o aumento da participação da mulher na esfera pública está relacionado à inclusão pelo consumo e à emergência, a cada contexto, de uma sempre "nova classe média”. Como descrito pela revista Veja, 71\% dessas "novas mulheres" tratam os cabelos em casa, consumindo produtos como "xampu, condicionador, creme para tratamento, óleo de silicone, máscara de tratamento, creme para pentear e gel de fixação" (Venturoli, 2010, p.77). Ainda segundo a reportagem, "apenas 7\% viajam tanto quanto gostariam - mas 86\% dizem querer fazer turismo nos próximos anos” (Venturoli, 2010, p. 77). E mais, consideram que "uma marca famosa é fundamental" (Venturoli, 2010, p. 77) em produtos como perfumes, sapatos e roupas.

As militantes do movimento dos anos 1960 e 1970 recusaram alianças com a esfera do consumo e assumiram a visão da publicidade e da cultura de massa em geral como manipulação e controle das mulheres. Mas o aumento expressivo da participação feminina no mercado de trabalho e na vida pública ao longo das últimas décadas do século XX suscitou novas formas de ativismo. As militantes contemporâneas, ou Grrls (Krolokke; Scott, 2006), parecem advogar, sobretudo, pela diversidade e multiplicidade nas teorias e práticas, contestando a existência de um ideal universal de feminilidade. Uma matéria da revista Elle de agosto 2013 resume o caráter plural e inclusivo do que seria o "novo feminismo":

O ativismo dos novos tempos libera a mulher para ser fashion e sensual, casar virgem, pintar o cabelo, batalhar pelos seus direitos, rebolar ou não fazer nada disso. [...] O feminismo hoje se apresenta de diferentes formas inclusive em cima de um palco, vestida de Givenchy decotado. Sua versão moderna visa ampliar as escolhas das mulheres e respeitar o desejo de cada uma, em contraponto à militância do passado, que reprimia tudo que pudesse parecer resultado da opressão machista, até nas coisas mais ingênuas, como a obrigação de estar com a depilação em dia. (Faria, 2013, p. 168-170).

Essa flexibilização do movimento pode envolver, inclusive, a fundamentação da autonomia feminina no consumo, agora representada por mulheres de grande projeção na mídia, como a "material girl” Madonna, a "single lady" Beyoncé, a "bad girl” Rihanna, entre outras. De fato, são recorrentes as produções midiáticas - revistas, filmes, séries de televisão, reality shows - que equacionam liberdade sexual e autonomia financeira da mulher com um projeto de consumo. Exemplo disso é o seriado Sex and the city (1998-2004), que

Horizontes Antropológicos, Porto Alegre, ano 22, n. 45, p. 217-247, jan./jun. 2016 
reproduz através de suas personagens uma concepção de "mulher moderna", que enfrenta dilemas profissionais e amorosos, sempre jovem e bem vestida com a última moda. Estudos observam esse alinhamento promovido pela mídia entre a autonomização da mulher e a cultura de consumo, e discutem seus impactos sobre as bases conceituais e manifestações do próprio feminismo (Banet-Weiser; Portwood-Stacer, 2006; McRobbie, 2008; Shugart; Waggoner; Hallstein, 2001).

No Brasil, a representação de uma "nova mulher" ganhou especial destaque nos últimos anos quando, em meio a uma crise global e à ascensão socioeconômica de milhões de brasileiros, um enxame de marcas internacionais desembarcou no país com expectativas de conquistar um novo mercado consumidor. Como na Europa do século XIX e no pós-guerra dos Estados Unidos, a "nova classe média" brasileira está longe de compor um todo homogêneo. Mas talvez o traço distintivo seja a efetiva inclusão de todos na esfera do consumo, ainda que suas capacidades pecuniárias se diferenciem e impliquem em limites variados. As filas de milhares de pessoas, em sua maioria mulheres, nas inaugurações da Forever 21 são emblemáticas desse cenário em que participar de acontecimentos no âmbito do consumo é fundamental à vida social contemporânea nas cidades brasileiras. Bem conhecida por um público dos segmentos medianos e altos da classe média, que já adquiriam seus produtos em viagens internacionais, a Forever 21 chegou ao Brasil mantendo seu posicionamento como uma marca jovem, acessível e, portanto, globalizante.

Em 30 anos de existência, a Forever 21 foi progressivamente alcançando reconhecimento internacional como um dos players mais importantes no cenário da moda de varejo. Como de costume entre os empreendedores burgueses, a história da Forever 21 está intimamente relacionada com a vida, os êxitos e a ascensão econômica e social de seus fundadores, o casal sul-coreano Dong-Won Chang e Jin Sook. Reza a lenda que no ano da primeira loja, então chamada Fashion 21, inaugurada em 1984, em Los Angeles, DongWon Chang trabalhava em um posto de gasolina para financiar a empresa familiar, enquanto sua esposa era encarregada de escolher as mercadorias que seriam postas à venda nas prateleiras. Em 1995, a empresa abriu suas primeiras lojas fora da Califórnia e em 2001 iniciou sua expansão para outros países, tais como Canadá, Reino Unido, Japão e China. Hoje em dia, apesar de ter mais de 500 lojas localizadas em alguns dos principais centros urbanos 
do mundo, a Forever 21 continua sendo essencialmente um negócio familiar, com o casal e suas duas filhas, Linda e Esther, respectivamente primogênita e caçula, ocupando posições de liderança na empresa. A filha mais velha é responsável pela área de marketing, enquanto a mais nova cuida do visual merchandising.

Junto com gigantes como a H\&M, TopShop, Zara e Desigual, a Forever 21 atua no mercado altamente competitivo do fast-fashion, que tem a missão central de oferecer aos consumidores roupas fashion por preços acessíveis, com uma recomposição incessante dos estoques de produtos. Essas lojas geralmente ocupam grandes espaços e prometem ofertar aos seus clientes uma ampla gama de opções de roupas e acessórios que se renovam durante todo o ano. Como vimos, esta modalidade de negócios lembra muito as estratégias e métodos iniciados com as primeiras lojas de departamentos na Europa desde a segunda metade do século XIX. Da mesma forma que os primeiros grandes magazines, a Forever 21 aposta em uma produção em larga escala para reduzir custos, acelerando assim a rotatividade de produtos e a entrada de receitas no caixa. Em suma, a lógica da multinacional consiste em tornar mais rápido e curto o fluxo de bens da produção ao consumo. Dessa forma, garante as barganhas e a permanente sensação de novidade aos jovens das classes médias que anseiam por desfilar com roupas da última moda.

Já no século XIX, as lojas de departamentos operavam, simultaneamente, um ambiente de produção fabril nos seus bastidores - de racionalização do trabalho, processos mecanizados e movimentos matematizados - e um espaço de magias aberto ao público, de vitrines e amplos salões decorados artisticamente, com cores, aromas e música (Rocha; Frid; Corbo, 2014). Da mesma forma, a Forever 21 constrói uma imagem jovem e cria uma atmosfera convidativa ao consumo, tanto através do design de suas lojas como por meio de anúncios publicitários e canais de venda on-line. Isso significa que, enquanto executa uma cadeia produtiva complexa, a empresa lança mão de diversos recursos para esconder a história social de suas mercadorias, promovendo jovialidade, descontração e atualidade para seus consumidores. Através de variados mecanismos do marketing e técnicas de vendas, a Forever 21 faz moda a preços baixos, convertendo continuamente roupas e acessórios em categorias de pessoas, estados de espírito e estilos de vida que se traduzem em um imaginário que inclui mágicas noções como heritage, minimalist, free spirit e, claro, modern femme. 
A eficácia da Forever 21 em tornar as compras uma experiência mais mágica que estritamente utilitária - como de resto se pode dizer do consumo em geral (Rocha, 1985; Wagner, 1975) - foi demonstrada pelas inaugurações brasileiras. Em uma série de depoimentos, disponíveis no YouTube, diversas clientes e bloggers de moda que compareceram aos eventos começam seus relatos com comentários sobre as filas longas e a lotação das lojas. No entanto, como sugerem suas narrativas, o tumulto e as horas de espera foram percebidos mais como um sinal de sucesso do que como um aspecto negativo ou uma "perda de tempo". A satisfação com a experiência de compras na nova loja parece justificar o sacrifício.

A associação entre a Forever 21 e os jovens é, enfim, outro fator importante para sua expansão. De fato, a marca capitaliza com a valorização, característica da cultura contemporânea, de um ideal de juventude que todos podem almejar, não importando a idade. O esticamento da categoria do jovem nas narrativas midiáticas se traduz em práticas de consumo inclusivas de indivíduos de todas as faixas etárias, sejam crianças, adolescentes, adultos ou idosos (Rocha; Pereira, 2009). Ao se dirigir a um público jovem, a Forever 21 potencializa sua capacidade de atingir um universo sempre mais amplo de consumidores. Inicialmente focada em moda feminina, a marca hoje conta com uma linha masculina e também para meninas e mulheres plus size. Como revelam seus catálogos on-line e comerciais de televisão, o conceito de juventude serve ao propósito de reunir pessoas de diversas idades em uma mesma experiência de consumo da marca. Assim, a Forever 21 tanto tem os consumidores jovens como alvo principal quanto inspira um determinado estilo extremamente amplo de ser jovem. Em suma, entre os múltiplos fatores que convergiram para formar as filas nas inaugurações das suas lojas no Brasil, a marca global, acessível, dominantemente feminina e jovem se alinha às expectativas de uma classe média em expansão.

\section{Consideracões finais}

Como destacamos ao longo do artigo, a formação e o imaginário das chamadas "novas classes médias" e o fenômeno do consumo guardam fortes relações entre si. Nos três exemplos aqui discutidos, um mesmo modelo de negócios, inaugurado ainda no século XIX com os grandes magazines, permanece balizando nossas atividades de consumo mais de 150 anos depois de sua 
criação e expandindo hábitos, gostos e poder de compra para uma parcela cada vez maior das populações urbanas. Os três diferentes contextos analisados contribuíram para a inclusão de camadas específicas da sociedade em experiências e espaços de consumo que antes eram restritos, contando especialmente com a mulher como vetor primordial nesses ciclos de expansão. Apesar do mesmo intuito e de práticas semelhantes, os empreendimentos analisados grandes magazines, shoppings e o varejo fast-fashion - guardam importantes particularidades que justificam o estudo de cada um deles. Em especial, a relação entre o consumo e a idealização da "mulher moderna" se trata de uma questão complexa que deve ser examinada em um projeto de pesquisa mais amplo.

Em suma, os grandes magazines contribuem para a formação de uma, talvez primeira, "nova classe média” na Europa através do barateamento dos preços, da política de tornar os produtos acessíveis a um maior número de consumidores e da capacidade de fazer de seus trabalhadores potenciais compradores, que entram em contato rotineiramente com o estilo de vida burguês. Os shoppings que surgem nos Estados Unidos no período subsequente à Segunda Guerra Mundial cumprem um importante papel no atendimento de outra "nova classe média” que migrava para os subúrbios e para as redondezas dos principais centros urbanos e, assim como os grandes magazines do século XIX, fazem com que seus funcionários tenham acesso ao universo do consumo através do contato com o público e da ascensão econômica. Por fim, o caso da marca contemporânea Forever 21 no Brasil evidencia uma estratégia de tornar acessível à assim chamada "nova classe média brasileira" uma série de produtos antes restritos a uma parcela mais rica da sociedade, com a promessa de apresentar sempre as últimas tendências da moda a preços baixos e carregando consigo um ideal abrangente da juventude. Em cada um desses contextos há um diálogo recorrente entre as estratégias de popularização do consumo, as "novas classes médias" e as representações da "mulher moderna”.

O que pretendemos mostrar nesse artigo é a relação íntima que o consumo possui com o surgimento, recrutamento e expressividade das "classes médias”, indicando a importância da mulher na articulação entre as inovações do comércio e a formação dos novos públicos que as sustentam. Este artigo busca destacar que, além do campo econômico e das transformações na esfera da produção, as experiências e as novas sensibilidades ligadas à cultura, ao simbólico e à dinâmica do consumo são esclarecedoras e extremamente ricas para

Horizontes Antropológicos, Porto Alegre, ano 22, n. 45, p. 217-247, jan./jun. 2016 
o entendimento da vida social na modernidade (Douglas; Isherwood, 2004; Rocha, 1985; Sahlins, 1979). Demonstramos que há uma profunda ligação entre o consumo, as camadas médias e a figura feminina capaz de atravessar diferentes sociedades e contextos históricos. É como se o consumo, a cada movimento, fizesse aparecer uma "nova classe média” vivificada pela força do imaginário em torno do feminino. O primeiro parece construir, articular e tornar visível a segunda, permitindo, através do protagonismo exercido pela recorrente idealização da mulher "moderna”, sua inclusão em práticas e espaços antes indisponíveis e oferecendo produtos e serviços, esses bens simbólicos, cujo valor também se encontra no seu potencial de expressividade para um determinado grupo. A análise sugere, no quadro das complexas relações entre economia e cultura, uma promissora perspectiva de pesquisa sobre a intrincada convergência entre o consumo e a expressão social das classes médias. Se, como ensinaram Marx e Engels (1978), a esfera da produção define o irreversível antagonismo entre burguesia e proletariado, as sempre "novas classes médias” são recrutadas e se expressam, sobretudo, através da outra ponta do processo econômico, a esfera do consumo.

\section{Referências}

AU BONHEUR des dames, l'invention du grand magasin. Direção: Sally Aitken; Christine Le Goff. Paris: Arte France: Essential Media \& Entertainment: Planète, 2011. Documentário para TV (85 min), color.

BANET-WEISER, S.; PORTWOOD-STACER, L. I just want to be me again! Beauty pageants, reality television and post-feminism. Feminist Theory, London, v. 7, n. 2, p. 255-272, 2006.

BEAUVOIR, S. de. Le deuxième sexe. Paris: Gallimard, 1949.

BONADIO, M. Moda e sociabilidade: mulheres e consumo na São Paulo dos anos 1920. São Paulo: Senac, 2007.

BRAZIL takes off: now the risk for Latin America's big success story is hubris. The Economist, New York, 14 Nov. 2009. Disponível em: <http:// www.economist.com/node/14845197>. Acesso em: 20 abr. 2015. 
CAMPBELL, C. A ética romântica e o espírito do consumismo moderno. Rio de Janeiro: Rocco, 2001.

CARVALHO, J. Chegada da Forever 21 pode atrapalhar concorrentes no Brasil. Exame.com, 20 mar. 2014. Disponível em: <http://exame.abril.com.br/ negocios/noticias/chegada-da-forever-21-pode-atrapalhar-concorrentes-nobrasil>. Acesso em: 15 nov. 2014.

DARNTON, R. O Iluminismo como negócio. São Paulo: Companhia das Letras, 1996.

DE GRAZIA, V.; FURLOUGH, E. (Ed.). The sex of things. Los Angeles: University of California Press, 1996.

DOUGLAS, M.; ISHERWOOD, B. O mundo dos bens: para uma antropologia do consumo. Rio de Janeiro: UFRJ, 2004.

FARIA, J. de. O novo feminismo. Elle, São Paulo, ano 26, n. 303, p. 168-170, ago. 2013.

GALHARDO, R. Lula: crise é tsunami nos EUA e, se chegar ao Brasil, será 'marolinha'. O Globo, 4 out. 2008. Disponível em: <http://oglobo. globo.com/economia/lula-crise-tsunami-nos-eua-se-chegar-ao-brasil-seramarolinha-3827410>. Acesso em: 10 nov. 2014.

GARCIA, M.; GIAMBIAGI, F. Risco e regulação: por que o Brasil enfrentou bem a crise financeira e como ela afetou a economia mundial. Rio de Janeiro: Campus, 2010.

GAY, P. O século de Schnitzler: a formação da cultura da classe média: 18151914. São Paulo: Companhia das Letras, 2002.

GOFFMAN, E. Gender advertisements. New York: Harper Torchbooks, 1987.

GOLDMAN, R.; HEATH, D.; SMITH, S. Commodity feminism. Critical Studies in Media Communication, Annandale, v. 8, n. 3, p. 333-351, 1991.

GORBERG, M. Parc Royal: um magazine na Belle Époque carioca. Rio de Janeiro: G. Ermakoff, 2013. 
GRIFE de moda jovem, Juicy Couture abre $1^{\text {a }}$ loja no Brasil. UOL Mulher, 18 fev. 2011. Disponível em: <http://mulher.uol.com.br/moda/noticias/ redacao/2011/02/18/grife-de-moda-jovem-juicy-couture-abre-1-loja-nobrasil.htm>. Acesso em: 20 abr. 2015.

HAHN, H. Scenes of Parisian modernity: culture and consumption in the nineteenth century. New York: Palgrave Macmillan, 2009.

KILBOURNE, J. Can't buy my love: how advertising changes the way we think and feel. New York: Simon \& Schuster, 2000.

KROLOKKE, C.; SCOTT, A. Three waves of feminism: from suffragettes to grrls. In: KROLOKKE, C.; SCOTT, A. Gender communication theories and analyses: from silence to performance. Thousand Oaks: SAGE, 2006. p. 1-24.

LANGELLIER, J.-P. et al. Le rebond de la croissance mondiale repose sur les BRIC. Le Monde, 16 set. 2009. Disponível em: <http://www.lemonde.fr/lacrise-financiere/article/2009/09/16/trois-grands-pays-emergents-le-bresil-lachine-et-l-inde-ont-retrouve-la-croissance_1241180_1101386.html>. Acesso em: 8 nov. 2014.

LEACH, W. Transformations in a culture of consumption: women and department stores. The Journal of American History, Bloomington, v. 71, n. 2, p. 319-342, 1984.

LIPOVETSKY, G.; ROUX, E. O luxo eterno. São Paulo: Companhia das Letras, 2005.

LUKÁCS, G. A consciência de classe. In: BERTELLI, A.; PALMEIRA, M.; VELHO, O. (Org.). Estrutura de classes e estratificação social. 3. ed. Rio de Janeiro: Zahar, 1971. p. 11-60.

MAD MEN. Los Angeles: AMC, 2007-2015. Série de TV.

MARX, K. Miséria da filosofia. Porto: Publicações Escorpião, 1974.

MARX, K. O Dezoito Brumário de Louis Bonaparte. São Paulo: Centauro, 2006.

Horizontes Antropológicos, Porto Alegre, ano 22, n. 45, p. 217-247, jan./jun. 2016 
MARX, K.; ENGELS, F. O manifesto comunista. 2. ed. Rio de Janeiro: Zahar, 1978.

McLUHAN, M. The mechanical bride: folklore of industrial man. Boston: Beacon Press, 1951.

McROBBIE, A. Young women and consumer culture. Cultural Studies, Abingdon, v. 22, n. 5, p. 531-550, 2008.

MEYEROWITZ, J. (Ed.). Not June Cleaver: women and gender in Postwar America, 1945-1960. Philadelphia: Temple University Press, 1994.

MICHAEL KORS abre primeira loja no Brasil no Rio de Janeiro. Terra, 18 jun. 2013. Disponível em: <http://moda.terra.com.br/michael-kors-abreprimeira-loja-no-brasil-no-rio-de-janeiro,b1e1c98c3e65f310VgnVCM20000 099cceb0aRCRD.html>. Acesso em: 20 abr. 2015.

MILLER, D. Teoria das compras: o que orienta as escolhas dos consumidores. São Paulo: Nobel, 2002.

MILLER, M. The Bon Marché. Princeton: Princeton University Press, 1981.

MR. SELFRIDGE. London: ITV Studios, 2013-. Série de TV.

NERI, M. A nova classe média: o lado brilhante da base da pirâmide. São Paulo: Saraiva, 2012.

O'NEILL, J. Building better global economic BRICs. New York: Goldman, Sachs \& Co, 2001. (Global Economics Paper no: 66).

PADILHA, V. Shopping center: a catedral das mercadorias. São Paulo: Boitempo, 2006.

POLANYI, K. A grande transformação. Rio de Janeiro: Elsevier, 2012.

RAPPAPORT, E. Uma nova era de compras: a promoção do prazer feminino no West End londrino, 1909-1914. In: CHARNEY, L.; SCHWARTZ, V. (Org.). O cinema e a invenção da vida moderna. São Paulo: Cosac \& Naify, 2001. p. 187-221. 
ROCHA, E. Magia e capitalismo: um estudo antropológico da publicidade. São Paulo: Brasiliense, 1985.

ROCHA, E. The woman in pieces: advertising and the construction of feminine identity. SAGE Open, Thousand Oaks, v. 3, n. 4, Oct. 2013. DOI: $10.1177 / 2158244013506717$.

ROCHA, E.; FRID, M.; CORBO, W. Negócios e magias: Émile Zola, Au Bonheur des Dames e o consumo moderno. Comunicação, Mídia e Consumo, São Paulo, v. 12, n. 32, p. 51-71, set./dez. 2014.

ROCHA, E.; PEREIRA, C. Juventude e consumo: um estudo sobre a comunicação na cultura contemporânea. Rio de Janeiro: Mauad X, 2009.

SAHLINS, M. Cultura e razão prática. Rio de Janeiro: Zahar, 1979.

SALOMÃO, K. The Body Shop abre loja no Brasil. Exame.com, 14 nov. 2014. Disponível em: <http://exame.abril.com.br/negocios/noticias/the-bodyshop-abre-loja-no-brasil>. Acesso em: 20 abr. 2015.

SCHELLER, F. Com bombom grátis, Lindt abre primeira loja no Brasil. Exame.com, 25 jul. 2014. Disponível em: <http://exame.abril.com.br/ negocios/noticias/com-bombom-gratis-lindt-abre-1a-loja>. Acesso em: 20 abr. 2015.

SEX AND THE CITY. New York: HBO, 1998-2004. Série de TV.

SHILLER, R. The subprime solution: how today's global financial crisis happened, and what to do about it. Princeton: Princeton University Press, 2008.

SHUGART, H.; WAGGONER, C.; HALLSTEIN, D. Mediating third-wave feminism: appropriation as postmodern media practice. Critical Studies in Media Communication, Annandale, v. 18, n. 2, p. 194-210, 2001.

SLATER, D. Cultura do consumo e modernidade. São Paulo: Nobel, 2002. 
TEIXEIRA, C. A.; CORRÊA, M. Apple inaugura primeira loja oficial no Brasil e da América Latina e atrai mais de 1.700 pessoas. O Globo, 15 fev. 2014. Disponível em: <http://oglobo.globo.com/sociedade/tecnologia/appleinaugura-primeira-loja-oficial-no-brasil-da-america-latina-atrai-mais-de1700-pessoas-11615580>. Acesso em: 20 abr. 2015.

TODESCHINI, M.; SALOMÃO, A. Um mergulho na nova classe média. Época Negócios, 5 nov. 2009. Disponível em: <http://epocanegocios.globo.com/ Revista/Common/0,ERT102795-16380,00.html>. Acesso em: 15 nov. 2014.

TOP 5 na Topshop: o que tem na loja paulistana - e quanto custa. Vogue, 28 jun. 2012. Disponível em: <http://revista.vogue.globo.com/moda/news/top-5na-topshop-o-que-tem-na-loja-paulistana---e-quanto-custa/>. Acesso em: 15 nov. 2014.

VELHO, G. Individualismo e cultura. Rio de Janeiro: Zahar, 1981.

VENTUROLI, T. A nova mulher da nova classe C. Veja, São Paulo, edição especial Mulher, p. 76-78, jun. 2010.

VERHEYDE, P. Les grands magasins parisiens. Paris: Balland Éditeur, 2012.

WAGNER, R. The invention of culture. Upper Saddle River: Prentice Hall, 1975.

WEBER, M. Classe, status, partido. In: BERTELLI, A.; PALMEIRA, M.; VELHO, O. (Org.). Estrutura de classes e estratificação social. 3. ed. Rio de Janeiro: Zahar, 1971. p. 61-83.

WEBER, M. Economia e sociedade. Brasília: UnB, 1999. 2 v.

WEBER, M. A ética protestante e o espírito do capitalismo. São Paulo: Martin Claret, 2004.

WRIGHT-MILLS, C. A nova classe média. 3. ed. Rio de Janeiro: Zahar, 1979.

YACCOUB, H. A chamada "nova classe média": cultura material, inclusão e distinção social. Horizontes Antropológicos, Porto Alegre, ano 17, n. 36, p. 197-231, jul./dez. 2011. 
ZOLA, É. O paraíso das damas. São Paulo: Estação Liberdade, 2008.

ZUINI, P. Clientes esperam até 5 horas para conhecer Forever 21. Exame.com, 15 mar. 2014. Disponível em: <http://exame.abril.com.br/negocios/noticias/ abertura-da-forever-21-tem-5-horas-de-filas>. Acesso em: 10 nov. 2014.

Recebido em: 22/04/2015

Aprovado em: 05/10/2015 